Szczecin

tel.: +48692679473

e-mail: jmbnew@wp.pl

ORCID ID: https://orcid.org/0000-0001-5439-2319

\title{
Фразеологизмы в газетных заголовках
}

Ключевые слова: газетные заголовки, фразеологизмы, цитаты, трансформации

Как утвержает Ли Якокка, представитель американского менеджмента, “большинство людей не читают газетные материалы целиком, а ограничиваются лишь чтением заголовков и подзаголовков" [Якокка 2017, 87]. Это потверждают исследования психологов, согласно которым $80 \%$ читателей уделяют внимание только заголовкам (за: [Алеева 2006, 73; Иноземцева 2015, 143]). Приведенные данные показывают каким существенным звеном между текстом и читателем является газетный заголовок: статья с неярким заглавием нередко не замечается.

Газетный заголовок - это речевой элемент, имеющий некую самостоятельность. Находясь перед основным текстом, он одновременно становится его частью, служащей для понимания текста статьи и выполняющей номинативную, информативную (фактуальную), прагматическую (рекламную, интригующую, воздействующую) и оценочно-экспрессивную функции.

В зависимости от степени сложности специалистами выделяются три типа заголовков: простой, усложненный и заголовочный комплекс. Простой заголовок, как известно, имеет форму простого предложения, выражающего законченную мысль ${ }^{1}$. По своему характеру он

1 Журналистика, [online], http://zhurnalistika.net/20110313786/teoriya-zhurnalistiki/ sekrety-dela/gazetnye-zagolovki-vidy-i-tipy.-klassifikatsciya.html, [24.10.2017]. 
может быть утвердительным или вопросительным, напр.: Календарь народных примет на вторую половину года (Аргументы и Факты [далее: $A$ $Ф$ ]. На даче № 22 от 21 ноября 2017) ${ }^{2}$, Как часто Совет Федерации отклоняет принятье Думой законь? АиФ № 49 от 07 декабря $2017)^{3}$. В свою очередь, усложненные заголовки состоят из нескольких самостоятельных, логически завершенных частей, представляющих некую законченную мысль. Так как и простые, они могут быть утвердительными или вопросительными предложениями, ср.: Eвропа двух скоростей. Почему растёт пропасть в уровне жизни в странах $E C$ ? $A$ $\Phi$ № 49 от 07 декабря 2017) ${ }^{4}$. Заголовочный комплекс состоит из основного заголовка и подзаголовков (дополнительных заголовков), которые появляются в начале каждой части статьи. Итак, статья Тень жёлтого монстра. Должен ли российский Дальний Восток бояться Китая? (основной заголовок) разделена на несколько частей, каждая из которых названа отдельным подзаголовком: Сбежали из-за рубля; Проще глотать Африку; «Есть у нас дураки» АиФ № 4 от 24 января 2018) ${ }^{5}$.

Придумать выделяющийся среди других заголовок - это настоящее искусство. Как показывают исследования языковедов (напр. [Ильясова 2001; Газда 2007]), эффективным способом привлечения внимания читателя является использование журналистами разнообразных приемов языковой игры, характерных прежде всего для рекламных текстов. В газетных заголовках можно встретиться с разными типами языковой игры. В языковую игру вовлекаются ресурсы разных уровней языка: графические (употребление латиницы, нестандартное использование прописных букв, повторение букв, применеиние дореволюционной орфографии, образование гибридных написаний и "слов-матрешек", использование дефиса, скобок, точки), фоностилистические (парономазия, аллитерация, тавтология), лексико-семантические, синтаксические (хиазм, парцелляция), словообразовательные.

В качестве заголовка используются также прецедентные феномены (интертекстемы ${ }^{6}$. Учитывая смысловую сомостоятельность таких

2 Аргументы и Факты, [online], http://www.aif.ru/gazeta/number/36397, [07.12.2017].

3 Аргументы и Фактьи, [online], http://www.aif.ru/gazeta/number/36523, [07.12.2017].

4 Там же.

5 Аргументь и Фактье, [online], http://www.aif.ru/politics/world/ten_zhyoltogo_mon stra_dolzhen_li_rossiyskiy_dalniy_vostok_boyatsya_kitaya, [26.01.2018].

6 См. напр. [Bartwicka 1994, 33-41]. 
заголовков и их связь с текстом статьи, Е. П. Черногрудова выделяет четыре типа заголовков:

1) заголовки, смысл которых не требует обращения читателя к тексту статьи;

2) заголовки, смысл которых становится понятным только после прочтения текста статьи;

3) заголовки с ложной интерпретацией, т.е. такие, которые интерпретируются сразу, но требуют повторной интерпретации после прочтения текста статьи;

4) заголовки с мнимопрецедентными текстами, в которых фразы прецедентных текстов используются в прямом значении [Черногрудова 2003].

Репертуар прецедентных феноменов, используемых в периодической печати довольно широкий. Они относятся к:

- художественной литературе, напр.: заголовок По ком звонит БигБен? (АиФ. Европа № 1 от 05 мая 2010) 7 - трансформация заглавия произведения По ком звонит колокол Э. Хэмингуэя; заголовок Жить или не жить (АиФ № 16 от 17 апреля 2013)8 - трансформация цитаты "Быть или не быть?" из пьесы Гамлет В. Шекспира);

- фильмам, скажем, заголовок «Судьба - внутри нас». Проблемы духовного поиска современного человека (АиФ № 7 от 14 февраля $2018)^{9}$ - трансформация цитаты "Некоторые говорят, что судьба от нас не зависит, что мы над ней не властны, но я знаю точно: наша судьба живет внутри нас. И нужна только храбрость, чтобы ее разглядеть..." из мультфильма Храбрая сердием, 2012;

- текстам популярных музыкальных произведений, например заголовок $А$ удача - награда за... трусость! (Комсомольскал правда № 16 от 18-25 апреля 2013)10 - трансформация строчки "А удача награда за смелость" из песни Надежда в исполнении А. Герман);

- фразеологии, напимер заголовок Овчинка cтоит выделки (Московский комсомолеи в Хабаровске № 15 от 3-10 апреля 2013) трансформация фразеологизма овчинка выделки не стоит) и другим интертекстемам.

7 Аргументы и Факты, [online], http://www.aif.ru/archive/1704572, [07.11.2017].

8 Аргументы и Факты, [online], http://www.aif.ru/society/healthcare/zhit_ili_ne_zhit_ nizhegorodskie_chinovniki_protiv_tyazhelobolnyh, [11.12.2017].

9 Аргументы и Факты, [online], http://www.aif.ru/gazeta/number/37026, [18.02.2018].

10 Комсомольская правда, [online], https://www.kp.ru/daily/26064.2/2972127/,

[11.12.2017]. 
Как видим, прецедентные тексты в газетных заголовках либо цитируются без изменений, либо подвергаются трансформации ${ }^{11}$.

Объектом исследования стали газетные заголовки, в создании которых применяются фразеологизмы. Иллюстративным материалом послужили бесплатные периодические издания онлайн Аргументов u Фактов за годы 2007, 2017 и начала 201812. Фразеологизмы в качестве газетных заголовков приводятся журналистами в канонической форме или подвергаются разного типа аналитическим трансформациям (изменение количества компонентов, синтаксическая и лексическая трансформация, контаминация, фразеологическая парономазия) [Лисичкина 2004, 70].

Прямое цитирование - это редкость ${ }^{13}$, напр. Малой кровью. Как убрать рубць на лице и теле (АиФ. Здоровье № 47 от 21 ноября

11 Как показывают работы исследователей, использование прецедентных текстов, в том числе фразеологизмов, в качестве газетных заголовков свойственное также многим зарубежным газетным изданиям, напр. польским: Stawnicka J., 2000, Innowacje frazeologiczne we wspólczesnych nagłówkach prasowych, [в:] Jezzyk trzeciego tysiaclecia. Zbiór referatów z konferencji, Kraków 2-4 marca 2000, G. Szpila (red.), Kraków, s. 207-214; Ślawska M., 2008, Tytut - najmniejszy tekst prasowy, "Rocznik Prasoznawczy" nr 118, t. 2, s. 117-12; немецким: Manerova K.V., 2015, Frazeologičeskie modifikacii $v$ nemeckom mediatekste: tipy $i$ dinamika, [v:] 43 Meždunarodnâ̂ filologičeskâ̂ konferenciâ.11-16.03.2014. Izbrannye trudy, Sankt-Peterburg, s. 240-25. [Манерова K.В., 2015, Фразеологические модификачии в немецком медиатексте: типь и динамика, [в:] 43 Международная филологическая конференция. 11-16.03.2014. Избраннье mpyдbl, Санкт-Петербург, с. 240-250]; Šelâeva E.A., 2016, Gazetnye zagolovki kak sredstvo vozdejstviâ na massovoe soznanie (na materiale nemeckoâzyčnoj pressy, "Master's journal" № 2, s. 548-556. [Шеляева Е.А., 2016, Газетные заголовки как средство воздействия на массовое сознание (на материале немецкоязычной прессы, "Маster's journal" № 2, с. 548-556]; английским: Aleeva A.В., 2006, K voprosu o leksičeskih osobennostâh britanskih gazetnyh zagolovkov (na materiale zagolovkov gazet The Times $i$ The Sun), "Vesnìk BDU", Seriâ 4, № 1, s. 73-78. [Алеева А.Б., 2006, K вопросу о лексических особенностях британских газетных заголовков (на материале заголовков газет The Times u The Sun), "Веснік БДУ", Серия 4, № 1, с. 73-78]; французским: Turčinskaâ È.I., 1987, Ispol'zovanie frazeologizmov v gazetnyh zagolovkah (na materiale francuzskoj i sovetskoj pressy), [v:] Sbornik nauč. trudov MGPIIÂA im. M. Toreza, vyp. 294, s. 47-55. [Турчинская Э.И., 1987, Использование фразеологизмов в газетных заголовках (на материале франиузской и советской прессь), [в:] Сборник науч. трудов МГПИИЯ им. М. Тореза, вып. 294, с. 47-55].

12 Проанализировано 12 номеров за январь, февраль и март 2018 года. В итоге в материялах за все эти годы среди около 7 тысяч газетных заголовков обнаружено лишь 0,5\% фразеологических заголовков, причем в некоторых номерах такие заголовки отсутствуют.

13 Cр. также Nemirova A.D., 2013, Âzykovâ̂ igra na osnove frazeologizmov i precedentnyh tekstov $v$ zagolovkah sovremennyh gazet, "Vestnik Moskovskogo gosudarstvennogo universiteta pečati", s. 153-157. [Немирова А. Д., 2013, Языковая игра на основе фразеологизмов и прецедентных текстов в заголовках современных газет, "Вестник Московского государственного университета печати", с. 153-157.]. 
$2017)^{14}$. Первая часть заголовка относится к одному из значений разговорного фразеологизма малой кровью - 'не затрачивая много усилий' [Федоров 2008, 539] и вполне передает суть статьи, в которой представлены нехирургические (консервативные) и неслолжные хирургические методы удаления рубцов. Такой тип заголовочных фразеологизмов разговорного и экспрессивного характера можно проиллюстрировать и другими примерами: Глаза в глаза. До 18 марта $\kappa$ вам дваждьи придут членье УИК и сотрудники МФЦ (АиФ № 5 от 31 января $2018)^{15}$, ср. глаза в глаза - 'совсем, совершенно рядом, очень близко' [Федоров 2008, 133]; В два сиёта! Что такое ментальная арифметика? АиФ. Здоровье № 5 от 30 января 2018)16, ср. в два счета - 'без промедления; очень быстро; сразу же' [Федоров 2008, 672]; Всё пропускал через сердче. Почему Броневой не захотел быть Гитлером (АиФ № 50 от 13 декабря 2017) $)^{17}$, ср. пропускать/пропустить через сердие (что) - 'прочувствовать, продумывать; субъективно оценивать' [Федоров 2008, 539]; Найти забытую Россию. Как вдохнуть жизнь в депрессивные регионы? (АиФ № 7 от 14 февраля 2018) ${ }^{18}$, ср. вдохнуть жизнь в кого - 'оживить, одухотворить кого-л.' [Федоров 2003, 60]. В качестве заголовков применяются и книжные фразеологизмы, напр.: В объятиях Морфея. 6 правил здорового сна (АиФ № 9 от 28 февраля 2018) ${ }^{19}$, ср. объятия Морфея 'о состоянии сна' [Берков, Мокиенко, Шулежкова, т. 2, 2008, 113]; «Городу и миру». Что в России и за рубежом услышали в послании Путина? (АиФ № 10 от 07 марта 2018) 20 , ср. крылатое выражение городу и миру (калька с лат. Urbi et orbi) - 'всему свету, всем без исключения, к всеобщему сведению, широковещательно (объявлять что-л.)' [Берков, Мокиенко, Шулежкова, т. 1, 2008, 273-274] и др. Встречаются и заголовочные фразеологизмы из сферы политики и экономии, например, Соииальный $\boldsymbol{л и \boldsymbol { m }}$ и миллион. Как готовят будущих российских управленцев (АиФ № 7

\footnotetext{
14 Аргументы и Факты, [online], http://www.aif.ru/health/secrets/maloy_krovyu_kak_ ubrat_rubcy_na_lice_i_tele, [21.11.2017].

15 Аргументы и Факть, [online], http://www.aif.ru/gazeta/number/36909, [31.01.2018].

16 Аргументы и Фактьи, [online], http://www.aif.ru/gazeta/number/36908, [31.01.2018].

17 Аргументьи и Фактье, [online], http://www.aif.ru/culture/person/vsyo_propuskal_ cherez_serdce_pochemu_bronevoy_ne_zahotel_byt_gitlerom, [13.12.2017].

18 Аргументы и Факты, [online], http://www.aif.ru/gazeta/number/37026, [18.02.2018].

19 Аргументы и Фактьи, [online], http://www.aif.ru/gazeta/number/37135?utm_source $=$ aif\&utm_medium $=$ free\&utm_campaign=main, [28.02.2018].

20 Аргументь и Факты, [online], http://www.aif.ru/gazeta/number/37185, [20.03.2018].
} 
от 14 февраля 2018)21, ср. соииальный лифm - 'общественный институт, облегчающий повышение социального статуса индивида'22 и пр.

Незначительные изменения (замена формы единственного числа множественной) происходят в заимстованном из английского языка выражении скелет в шкафу в значении 'о чем-л. весьма неприглядном, о семейной (корпоративной) тайне, которую пытаются скрыть' [Берков, Мокиенко, Шулежкова, т. 2, 2008, 351-352], ср. В ЦИК с повинной. Какие скелеть в шкафу прячут кандидать в президенты? (АиФ № 3 от 17 января 2018) ${ }^{23}$.

Чаще всего фразеологизмы в газетных заголовках подвергаются разного типа трансформациям, типа: замена (субституция), редукция или расширение состава устойчивого словосочетания. В некоторых случаях имеет место несколько способов преобразования исходного текста.

С целью придания заголовкам нового смыслового оттенка компоненты фразеологизма могут замещаться новыми (лексическая трансформация). Итак, восходящая к библейскому источнику - изречению Саломона "Сеющий неправду пожнет беду", а также связанная с соответсвующим местом послания Павла к Галатам "Что посеет человек, то и пожнет" - пословица Что посеешь, то и пожнешь в значении 'за свои поступки, неблаговидные действия приходится расплачиваться' [Берков, Мокиенко, Шулежкова, т. 2, 2008, 565] подвергается структурной модификации благодаря замене компонента посеешь лексемой прочтем. Дополнительно грамматическая форма 2. лица ед.ч. заменяется формой 1. лица мн. ч. В итоге заголовок приобретает форму Что прочтем - то пожнем (АиФ № 9-10 от 18 мая 2007) ${ }^{24}$. Такая трансформация фразеологизма становится понятной только после прочтения статьи. В ней говорится о важности литературного воспитания детей, особенно о влиянии самых первых произведений на формирование нравственного мира подростка. Структурная трансформация фразеологизма способствует модификации его значения, которое в отличие от канонического приобретает положительный оттенок - 'с течением времени получаем положительные результаты от разумного воспитания детей'.

21 Аргументы и Фактьи, [online], http://www.aif.ru/gazeta/number/37026, [18.02.2018].

22 Викисловарь, [online], https://ru.wiktionary.org/wiki/\%D1\%81\%D0\%BE\%D1\%86\% D0\%B8\%D0\%B0\%D0\%BB\%D1\%8C\%D0\%BD\%D1\%8B\%D0\%B9_\%D0\%BB\%D0\%B8\% D1\%84\%D1\%82, [18.02.2018].

23 Аргументы и Фактьи, [online], http://www.aif.ru/gazeta/number/36800, [17.01.2018].

24 Аргументь и Фактьи, [online], http://www.aif.ru/gazeta/number/22263, [04.10.2017]. 
В очередном примере Дамоклов мяч (АиФ № 46 от 15 ноября $2017)^{25}$ субституции подвергся компонент меч, ср. каноническую форму фразеологизма дамоклов меч книжн. или публ. 'о постоянно грозящей кому-л. опасности' [Берков, Мокиенко, Шулежкова, т. 1, 2008, 292-293]. Замена компонентов не случайна - речь идет о трудной ситуации в сборной России, ротации тренеров и участии футболистов на чемпионате мира. В этом случае созвучный лексический компонент газетного заголовка служит созданию фразеологической парономазии.

Первая часть усложненного заголовка Не Байкалом единым. В Иркутской области много уникальных мест (АиФ № 48 от 29 ноября 2017) ${ }^{26}$ восходит к библеизму не хлебом единым [жив человек] в значении 'человеку следует заботиться об удовлетворении не только материальных, но и духовных потребностей, ибо он не может обойтись без духовного начала: для него духовные потребности не менее важны, чем материальные' [Берков, Мокиенко, Шулежкова, т. 2, 2008, 84-85]. Смысл фразеологизма в заголовке подвергается незначительной модификации (обращается внимание лишь на духовную сторону жизни), чему способствует замена компонента хлебом лексемой Байкалом. В статье автор пишет о духовных потребностях общества, обращая при этом внимание, что наслаждать душу можно не только созерцанием озера Байкал, но и другими природными достопримечательностями Иркутской области.

В газетных заголовках встречаются также мнимые трансформации фразеологизмов. На первый взгляд начало газетного заголовка Абу-Даби мастера боится. Кто принёс России победу в чемпионame WorldSkills? (AuФ № 44 от 1 ноября 2017) ${ }^{27}$ кажется трансформацией (чему способствует замена компонента дело лексемой $A б y$-Даби) крыловской фразы дело мастера боится в значении 'в умелых руках любое дело спорится' [Берков, Мокиенко, Шулежкова, т. 1, 2008, 304]. Однако после прочтения статьи становится ясным, что заголовок - это маркетинговая уловка, призванная привлечь внимание читателя именно на эту статью. Дело в том, что смысл заголовка следует понимать буквально. Мастера - это представители Российской Федерации, побе-

25 Аргументы и Фактье, [online], http://www.aif.ru/sport/opinion/damoklov_myach, [16.011.2017].

26 Аргументы и Факты, [online], http://www.aif.ru/travel/ne_baykalom_edinym_v_irku tskoy_oblasti_mnogo_unikalnyh_mest, [06.12.2017].

27 Аргументы и Фактыл, [online], http://www.aif.ru/money/business/abu-dabi_mastera _boitsya_kto_prinyos_rossii_pobedu_v_chempionate_worldskills, [07.11.2017]. 
дители чемпионата WorldSkills, который состоялся в Абу-Даби. Чемпионы на протяжении 5 лет с 41 места продвинулись на 1 место.

В приводимых ниже примерах заголовочные фразеологизмы представляют собой усеченную форму канонических выражений, напр. И в огонь, и в воду... Станут ли поличейские нашими ангелами-хранителями? (АиФ № 48 от 29 ноября 2017) ${ }^{28}$, ср. библеизм ид$m u /$ пйти в огонь и в воду за кого, что разг. 'быть готовым испытывать любые трудности, опасности [ради кого-, чего-л.]' [Берков, Мокиенко, Шулежкова, т. 1, 2008, 428]; Чаша сия: как «АиФ» за «Лужники» боролись (АиФ № 1-2 от 10 января 2018 $)^{29}$, ср. библеизм да минует меня чаша сия в значении 'пусть обойдет меня стороной эта беда, горе, несчастье' [Берков, Мокиенко, Шулежкова, т. 1, 2008, 291-292]. При этом следует подчеркнуть, что семантика трансформированных фразеологизмов не подвергается изменению.

Среди заголовочных фразеологизмов находятся и такие, в которых появляются добавочные компоненты, служащие уточнению значения, напр.: Ёлки XXI века. Оригинальньле хвойньее для тех, кто идёт в ногу со временем (АиФ. Здоровье № от 21 декабря 2017) ${ }^{30}$, ср. идти в ногу в двух значениях: 1. с кем. 'действовать согласованно с кем-л.' и 2. с кем 'поступать сообразно принятым правилам, нормам' [Федоров 2008, 268]; “Троянский конь” реформы $\boldsymbol{Ж} \boldsymbol{K} \boldsymbol{X}^{31}$ (АиФ. Долгожитель № 7-8 от 13 апреля 2007) ${ }^{32}$, ср. троянский конь в значении 'подарок, приносящий ущерб принимающему' [Берков, Мокиенко, Шулежкова, т. 2, 2008, 458] ${ }^{33}$; Ольга Бузова: «Я - белая ворона с меткой из гудрона (АиФ. Про Здоровье № 12 (122) от 11 ноября 2017) ${ }^{34}$, ср. белая ворона неодобр. 'о человеке, резко отличающемся от других, не таком, как все' [Берков, Мокиенко, Шулежкова, т. 1, 2008, 95].

В некоторых заголовках добавочные компоненты содействуют синтаксической трансформации. В соответсвующих примерах предикатив нельзя и отрицательная частица не способствуют созданию антоними-

\footnotetext{
28 Аргументы и Фактьи, [online], http://www.aif.ru/society/safety/i_v_ogon_i_v_vodu_a inogda_vo_vse_tyazhkie_k_chemu_privela_reforma_mvd, [06.12.2017].

29 Аргументы и Фактьи, [online], http://www.aif.ru/society/media/chasha_siya_kak_aif za_luzhniki_borolis, [11.01.2018].

30 Аргументы и Фактьи, [online], http://www.aif.ru/gazeta/number/36624, [11.01.2018].

31 ЖКХ - жилищно-коммунальное хозяйство.

32 Аргументы и Факты, [online], http://www.aif.ru/archive/1683639, [04.10.2017].

33 Этим “подарком" является жилищно-коммунальная реформа в России.

34 Аргументы и Фактье, [online], http://www.aif.ru/culture/person/olga_buzova_ya_ belaya_vorona_s_metkoy_iz_gudrona, [21.11.2017].
} 
ческих значений, напр.: Нал нельзя складывать крылья (АиФ № 29 от 19 июля 2017 $)^{35}$, ср. складыввать/сложить крылья ирон. 'смиряться с чем-л., прекращать борьбу'36; Их дело - не сторона. Московские профсоюзы пригласят горожан на выьборь (АиФ № 4 от 24 января $2018)^{37}$, ср. мое (твоё и т. п.) дело сторона прост. экспрес. 'совершенно не касается (меня, тебя и т. д.) что-л.' [Федоров 2008, 183].

Другой тип синтаксической трансформации представляет следующий заголовок: Когда рубль перестал быть «деревянным» (AиФ № 5 от 31 января 2018) ${ }^{38}$, ср. деревянный рубль ирон.'о российских рублях, обладающих низкой покупательной способностью, подверженных быстрому обесцениванию в связи с инфляцией' [Толковый... 2006, 299], в котором меняется синтаксическая функция исходной формы фразеологизма. Каноническая форма фразеологизма может выполнять функцию подлежащего или второстепенного члена предложения; в приведенном примере компонент рубль выступает в роли подлежащего, а прилагательное деревянным является именной частью составного сказуемого.

Следующим примером аналитической трансформации является контаминация. В наших источниках результатом скрещивания 39 двух фразеологизмов является газетный заголовок Дойная священная корова. Как России получить миллиарды от туризма по примеру Индuи? Его образуют фразеологизмы дойная корова (неодобр.): 'о ком-, чем-л., как о безотказном источнике дохода' [Берков, Мокиенко, Шулежкова, т. 1, 2008, 320] и священная корова (публ. неодобр.). Последний имеет два значения: 1. 'нечто, чрезвычайно ценное, не подлежащее дележу, расходованию', 2. 'те, кого нельзя трогать (критиковать, судить); то, что нельзя менять, нечто неприкосновенное' [Берков, Мокиенко, Шулежкова, т. 2, 2008, 329]. Смысл же самого заголовка разъясняет отрывок из текста статьи: “Даже в самых убогих отелях Индии приезжий остаётся дорогим гостем. Турист у нас священная коро-

35 Аргументы и Фактьи, [online], http://www.aif.ru/gazeta/number/35361?utm_source =aif\&utm_medium =free\&utm_campaign=main, [20.07.2017].

36 Большой словарь русских поговорок, [online], http://dic.academic.ru/dic.nsf/prover bs $/ 27723 / \%$ D0\%A1\%D0\%BA\%D0\%BB\%D0\%B0\%D0\%B4\%D1\%8B\%D0\%B2\%D0\%B0\% D1\%82\%D1\%8C_, [30.01.2018].

37 Аргументы и Факты, [online], http://www.aif.ru/gazeta/number/36852, [14.01.2018].

38 Аргументы и Фактьи, [online], http://www.aif.ru/gazeta/number/36909, [31.01.2018].

39 Общим элементом контаминированных фразеологизмов явлется компонент корова. При линейном соединении два фразеологизма следуют один за другим. В наших источниках такие примеры не обнаружены. 
ва, а у вас его рассматривают как дойную" (АиФ № 45 от 08 ноября 2017$)^{40}$.

В заголовке В иужом глазу - соринка, а в своем - бревно! (АиФ. Долгожитель № 9-10 от 18 мая 2007) ${ }^{41}$ исходное значение фразеологизма сохраняется. Однако при сравнении с библеизмом видеть сучок в чужом глазу [и не видеть бревна в своем] 'подметать чьи-л. мелкие недостатки, промахи, не обращая внимания на свои, более крупные' [Берков, Мокиенко, Шулежкова, т. 1, 2008, 170] выявляются следующие преобразования: инверсия, редукция начального компонента и субституция компонента (сучок : соринка).

Приведенный иллюстративный материал показывает, что среди представленных примеров больше всего аналитических трансформаций, которым иногда сопутствует модификация значений, вплоть до создания антонимии. Более того, в качестве заголовков используются выражения не только нейтрального характера, но и с различной стилистической окраской (книжные, разговорные и просторечные).

Творческое преобразование заголовочных фразеологизмов (в подавляющем числе паремий, часть из которых восходит к Библии) придает заголовкам яркость, броскость, остроумность, эффект новизны, усиливает эмоциональность и экспрессивный характер названий статей, иногда служащий созданию иронического эффекта и языковой игры. В свою очередь, игровой характер заголовков побуждает потенциального адресата ознакомиться с текстом статьи, способствует виртуальному диалогу журналиста с читателем.

\section{Literatura}

Aleeva A.B., 2006, K voprosu o leksičeskih osobennostâh britanskih gazetnyh zagolovkov (na materiale zagolovkov gazet The Times $i$ The Sun), "Vesnik BDU", Seriâ 4, № 1, s. 73-78. [Алеева А.Б., 2006, K вопросу о лексических особенностях британских газетных заголовков (на материале заголовков газет The Times u The Sun), "Веснік БДУ", Серия 4, № 1, с. 73-78.]

Berkov V.P., Mokienko V.M., Šuležkova S.G., 2008, Bol'šoj slovar' krylatyhslov i vyraženij russkogo âzyka, t. 1-2, Magnitogorsk, Greifswald. [Берков В.П., Мокиенко В.М., Шулежкова С.Г., 2008, Большой словарь крылатых слов и выражений русского языка, т. 1-2, Магнитогорск, Greifswald.]

40 Аргументы и Факты, [online], http://www.aif.ru/money/market/doynaya_svyash chennaya_korova_kak_rossii_razvit_turizm_po_primeru_indii, [13.11.2017].

41 Аргументы и Факты, [online], http://www.aif.ru/archive/1683687, [04.10.2017]. 
Bol'šoj frazeologičeskij slovar' russkogo âzyka, 2006, Teliâ V.N. (otv. red.), Moskva. [Большой фразеологический словарь русского языка, 2006, Телия В.Н. (отв. ред.), Москва.]

Bol'šoj slovar' russkih pogovorok, [Большой словарь русских поговорок], [online], http://dic.academic.ru/dic.nsf/proverbs/27723/\%D0\%A1\%D0\%BA\%D0\%B B\%D0\%B0\%D0\%B4\%D1\%8B\%D0\%B2\%D0\%B0\%D1\%82\%D1\%8C_, [30.01.2018].

Gazda J., Oterželova Â., Âzykovâa igra v gazetnyh zagolovkah, [Газда Й., Отержелова Я., Языковая игра в газетных заголовках], [online], https://is. muni.cz/el/1421/podzim2007/rjb_16/um/hra_titulky.pdf, [24.03.2018].

Egor'ev N.A., 1999, Gazetnyj zagolovok kak aktivizator fonovyhznanij, "Filologičeskie nauki" № 1, s. 90-95. [Егорьев Н.А., 1999, Газетный заголовок как активизатор фоновых знаний, "Филологические науки" № 1 , c. $90-95$.]

Il'âsova S., 2001, Âzykovâa igra v gazetnom tekste, "Relga", № 23 [Ильясова C., 2001, Языковая игра в газетном тексте, "Relga", № 23], [online], http:// www.relga.ru/Environ/WebObjects/tgu-www.woa/wa/Main?textid=395\& level1 $=$ main\&level2 $=$ articles, [01.12.2018].

Inozemceva N.V., 2015, Funkcional'nye osobennosti zagolovkovangloâzyčnyh gazetnyh stat'ej, "Vestnik Orenburgskogo gosudarstvennogouniversiteta" № 11 (196), s. 142-146. [Иноземцева Н. В., 2015, Функииональные особенности заголовков англоязычных газетных статьей, "Вестник Оренбургского государственного университета" № 11 (196), с. 142-146.]

Lisičkina I., 2004, Znakomye neznakomcy, "Žurnalistika i kul'tura russkoj reči" № 2, s. 69-75. [Лисичкина И., 2004, Знакомые незнакомцье, "Журналистика и культура русской речи" № 2 , с. $69-75$.$] .$

Manerova K.V., 2015, Frazeologičeskie modifikacii v nemeckom mediatekste: tipy i dinamika, [v:] 43 Meždunarodnâ̂ filologičeskâ̂ konferenciâ. 11-16.03.2014. Izbrannye trudy, Sankt-Peterburg, s. 240-25. [Манерова K.B., 2015, Фразеологические модификации в немецком медиатексте: типы и динамика, [в:] 43 Международная филологическая конференция. 11-16.03.2014. Избранные труды, Санкт-Петербург, с. 240-250].

Nemirova A.D., 2013, Âzykovâa igra na osnove frazeologizmov i precedentnyh tekstov $v$ zagolovkah sovremennyh gazet, "Vestnik Moskovskogo gosudarstvennogo universiteta pečati", s. 153. [Немирова А.Д., 2013, Языковая игра на основе фразеологизмов и прецедентных текстов в заголовках современных газет, "Вестник Московского государственного университета печати", с. 153-157.].

Podčasov A.S., 2000, Dezorientirun̂sie zagolovki v sovremennyh gazetah, "Russkaâ reč'” № 3, s. 52-55. [Подчасов А.С., 2000, Дезориентирующие заголовки в современных газетах, "Русская речь" № 3, с. 52-55.].

Prohorova K.V., 2005, Gazetnyj zagolovok: problemy i funkcional'nye vozmožnosti, Sankt Peterburg. [Прохорова K.В., 2005, Газетньий заголовок: проблемьь и функииональные возможности, Санкт Петербург.] 
Ratajčik K., 2008, Aktualizaciâ frazeologizmov v gazetnyh zagolovkah (na materiale russkoj pressy), "Acta Universitatis Lodziensis Folia Linguistica Rossica" nr 4, s. 147-156. [Ратайчик K., 2008, Актуализачия фразеологизмов в газетных заголовках (на материале русской прессы), "Acta Universitatis Lodziensis Folia Linguistica Rossica" nr 4, s. 147-156.]

Tolkovyj slovar' russkogo âzyka načala XXI veka. Aktual'nâ̂a leksika, 2006, G.N. Sklârevskaâ (red.), Moskva. [Толковый словарь русского языка начала ХХІ века. Актуальная лексика, 2006, Г.Н. Скляревская (ред.), Москва.]

Turčinskaâ È.I., 1987, Ispol'zovanie frazeologizmov v gazetnyh zagolovkah (na materiale francuzskoj $i$ sovetskoj pressy), [v:] Sbornik nauč. trudov MGPIIÂA im. M. Тогеza, vyp. 294, s. 47-55. [Турчинская Э.И., 1987, Использование фразеологизмов в газетных заголовках (на материале франиузской и советской прессь), [в:] Сборник науч. трудов МГПИИЯ им. М. Тореза, вып. 294, с. 47-55.]

Fedorov A.I., 2008, Frazeologičeskij slovar' russkogo literaturnogo âzyka, Moskva. [Федоров А.И., 2008, Фразеологический словарь русского литературного языка, Москва.]

Černogrudova E.P., 2003, Zagolovki s precedntnymi tekstami v sovremennoj publicistike: na materiale central'noj, regional'noj $i$ mestnoj pressy. [Черногрудова Е.П., 2003, Заголовки с прецеднтными текстами в современной публицистике: на материале чентральной, региональной и местной прес$c b l$, [online], http://www.dissercat.com/content/zagolovki-s-pretsedentnymi -tekstami-v-sovremennoi-publitsistike-na-materiale-tsentralnoi-reg\#ixzz50a n2GynJ, [11.12.2017].

Šelâeva E.A., 2016, Gazetnye zagolovki kak sredstvo vozdejstviâ na massovoe soznanie (na materiale nemeckoâzyčnoj pressy, "Master's journal" № 2, s. 548-556. [Шеляева Е.А., 2016, Газетные заголовки как средство воздействия на массовое сознание (на материале немецкоязычной прессь, "Master's journal" № 2, c. 548-556].

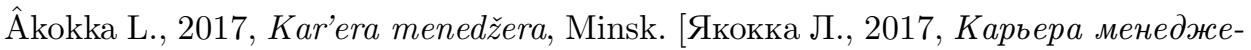
pa, Минск.]

Bartwicka H., 1994, Zabieg trawestacji jako środek stylistyczny nagłówków prasowych (na przykładzie jezyka rosyjskiego), "Studia Filologiczne" Filologia Rosyjska 16 , z. 39 , s. 33-41.

Ślawska M., 2008, Tytut - najmniejszy tekst prasowy, "Rocznik Prasoznawczy" nr 118 , t. 2 , s. $117-126$.

Słownik terminologii medialnej, 2006, W. Pisarek (red.), Kraków.

Stawnicka J., 2000, Innowacje frazeologiczne we współczesnych nagłówkach prasowych, [в:] Język trzeciego tysiaclecia. Zbiór referatów z konferencji, Kraków 2-4 marca 2000, G. Szpila (red.), Kraków, s. 207-214. 


\section{PHRASEMES IN PRESS HEADLINES}

\section{S U M M A R Y}

Key words: press headlines, phrasemes, quotes, transformations

Knowingly constructed press headline is a crucial element of press, being an advertisement of its kind. It is no surprise reporters in order to attract attention, frequently use precedent texts as headlines - titles and texts excerpted from literature, movies, songs; phrasemes. The article presents headlines from a weekly paper "Аргументы и факты" in which initial and modified forms of phrasemes were used. It is noted that journalists employ neutral, colloquial and literary expressions. Cited examples come from 2007, 2017 and the first quarter of 2018 online editions of the paper. 